\title{
O ENSINO DE FÍSICA NA FORMAÇÃO DO TÉCNICO EM EDIFICAÇÕES DO IFPA CAMPUS SANTARÉM
}

\author{
Saulo de Almada Gomes*; Adriana Oliveira dos Santos; Damião Pedro Meira Filho \\ *E-mail: saulo2492@hotmail.com \\ Instituto Federal de Educação, Ciência e Tecnologia do Pará \\ DOI: 10.15628/rbept.2020.9547
}

Artigo submetido em: fev/2020 e aceito em: mar/2020

\begin{abstract}
RESUMO
O objetivo deste estudo foi analisar as relações existentes entre a disciplina Física e as Disciplinas Específicas do Curso Técnico em Edificações do IFPA Campus Santarém, identificando as possibilidades de integração para a promoção do perfil de formação esperado ao egresso deste curso. Tendo por base a abordagem Qualitativa de Lüdke (2013), realizou-se Estudo Bibliográfico e Análise Documental. Para análise dos dados levantados, utilizou-se a metodologia de Moraes (1999), descrita como Análise Textual Discursiva. Observou-se, nessa pesquisa, que é necessária uma compreensão mais abrangente do ensino de Física, a qual não se limita ao suporte às disciplinas específicas Técnicas, mas se direciona a pressupostos e finalidades que abarcam vertentes pretendidas no Ensino Médio Profissional: a formação científico-tecnológica e humana.
\end{abstract}

Palavras-Chave: Ensino de Física. Ensino Médio Integrado. Técnico em Edificações.

\section{PHYSICS TEACHING IN THE CONSTRUCTION TECHNICIAN FORMATION OF IFPA SANTARÉM CAMPUS}

\begin{abstract}
This study aimed to analyse the relations between the subject Physics and the specific subjects of the Construction Technician Course of IFPA - Santarém Campus, spotting the possibilities of integration in order to provide the expected formation egress profile of this course. With Lüdke (2013) Qualitative Approach as background a bibliographycal study and document analysis were carried out. For data analysis Moraes (1999) methodology was used, which is described as Discourse Text Analysis. It was possible to notice from this research that a broader understanding teaching Physics is needed, which means one that is not limited to the support of the specific technical subjects, but aimed to assumptions and goals that cover the intended ways in the professional high school: the human technological scientifical formation.
\end{abstract}

Keywords: Physics teaching. Integrated High school. Construction Technician. 


\section{INTRODUÇÃO}

A disciplina Física é fundamental no processo de formação de cursos Técnicos em Edificações, pois é desta ciência que nasce grande parte de conceitos empregados e contextualizados dentro da área da Construção Civil (JACQUES et. al. 2011).

O curso Técnico em Edificações do IFPA Campus Santarém, desenvolvido na modalidade Integrado ao Ensino Médio, possui estrutura formativa de acordo com o Catálogo Nacional dos Cursos Técnicos. São correlacionados dois grupos de componentes curriculares: o grupo de Componentes Curriculares de Formação Básica (CCFB) e o grupo de Componentes Curriculares Específicos (CCE). O grupo de CCFB é composto por disciplinas da base comum do ensino médio, como é o caso da Física. Já o grupo de CCE, é composto por disciplinas Técnicas Profissionais, que são ligadas a um eixo Tecnológico, como é o caso das disciplinas 'Obras Geotécnicas', 'Instalações Prediais' e 'Tecnologia dos Materiais', por exemplo (PPC, 2016).

É estabelecido no Projeto Pedagógico do Curso (PPC) que os CCFB são desenvolvidos visando formação humana, social, cultural e cidadã do Técnico em Edificações. Esta perspectiva de formação está de acordo com a formação Integral do discente do ensino médio, proposta pela Lei o 9.394/96, que estabelece as Leis de Diretrizes e Bases da Educação (LDB). Os CCFB possibilitam ainda, a partir dos conhecimentos técnico-científicos de sua área, fundamentação, contextualização e aplicação para as disciplinas Técnicas. Já os CCE visam desenvolver um conjunto de habilidades e competências necessárias para o desenvolvimento das atividades específicas do profissional da área (PPC, 2016).

Visualizando esta proposta de Componentes Curriculares, entende-se que é importante a articulação entre as disciplinas dos CCFB e CCE desenvolvidos no curso, em que sejam trabalhadas habilidades $e$ competências comuns, a partir da identificação de conceitos comuns entre as disciplinas. Do mesmo modo, é importante que esta proposta de formação integral, bem como a articulação entre as disciplinas deste itinerário formativo, sejam previstas formalmente no PPC do respectivo curso, na definição de objetivos e ementas dos seus componentes curriculares e na descrição dos pressupostos e finalidades do perfil de formação do curso.

O conhecimento da importância de se correlacionar conceitos de disciplinas dos dois agrupamentos de Componentes Curriculares, além de saber se essa relação está acontecendo no Projeto Pedagógico do Curso, e qual o seu impacto para o perfil de formação do egresso do curso Técnico em Edificações, foi a motivação para esta pesquisa.

A partir desta inspiração, fez-se o seguinte questionamento: qual a relação que existe entre os temas e conceitos desenvolvidos na Disciplina Física com os temas e conceitos desenvolvidos nas disciplinas Técnicas e qual 
a sua contribuição para a formação do técnico em edificações do IFPA Campus Santarém?

Por isso, buscou-se nessa pesquisa, analisar as relações existentes entre a Disciplina Física e as Disciplinas Específicas Técnicas, a partir dos temas e conceitos das respectivas disciplinas apresentados no PPC, identificando as possibilidades de integração para a promoção do perfil de formação esperado ao egresso deste curso.

Ancorado na abordagem Qualitativa segundo Lüdke (2013), esta pesquisa ocorre em um ambiente tendo o pesquisador como seu principal instrumento, em que os dados coletados são predominantemente descritivos e no qual a preocupação com o processo é muito maior do que com o produto. Nesta pesquisa realizou-se Estudo Bibliográfico e Análise Documental.

No Estudo Bibliográfico se buscou conhecer referenciais que discutissem o ensino de Física no Ensino Médio, além de perspectivas de formação profissional integrada ao ensino médio, afim de ter orientação sobre a formação profissional do Técnico em Edificações formado por este curso. Utilizou-se subsídios de autores como Ciavatta (2005), Chiquetto (2011), Garcia, Rocha e Costa (2009), Menezes (2000), Moreira (2000) e Ramos (2005), para o desenvolvimento da discussão teórica e análise dos documentos.

A Análise Documental, de acordo com Lüdke (2013), avalia documentos formais ou informais com uma abordagem qualitativa, acerca de informações sobre um problema de pesquisa. Nesse trabalho, estudou-se documentos oficiais sobre formação do Ensino Médio e o PPC do curso Técnico em Edificações.

Durante a análise dos documentos oficiais da educação, como a Lei de Diretrizes e Bases da Educação - Lei no 9.394/96, a Lei de reforma do Ensino Médio - Lei ํo13.415/17, as Diretrizes Curriculares Nacionais para a Educação Profissional Técnica de Nível Médio, os Parâmetros Curriculares Nacionais para o Ensino Médio (PCNEM) e a Base Nacional Comum Curricular (BNCC), buscou-se conhecer os temas, conceitos, habilidades e competências, previstos para a disciplina de Física, além das perspectivas de formação de um educando do ensino médio.

No PPC do curso, mapeou-se os temas e conceitos de Física e das Disciplinas Técnicas abordados, a fim de compará-los e verificar as relações existentes. Além disso, observou-se a perspectiva de formação, dentro dos pressupostos e finalidades apresentadas nos componentes curriculares e no perfil de formação do PPC.

Tendo como lócus do estudo o Curso Técnico Integrado de Edificações do IFPA Campus Santarém, o recorte temporal foi de 2016 a 2019, devido a vigência do PPC do curso ser deste período (PPC, 2016).

A análise dos documentos, interligada aos aspectos teórico-conceituais presentes no referencial teórico, foi desenvolvida a partir da Análise Textual Discursiva proposta por Moraes (1999). Esta abordagem de análise se 
apresenta no sentido da categorização, descrição e interpretação dos dados levantados na pesquisa, e com a perspectiva de ligação dos significados investigados com a experiencia dos autores.

Dentro da metodologia de Moraes (1999), são definidas seis categorias de objetivos de pesquisa, levando-se em conta o conteúdo e as inferências pretendidas. Esta pesquisa tem como objetivo de análise, dentre as seis categorias, "para dizer o quê?", a qual direciona o olhar analítico para "as características da mensagem propriamente dita, seu valor informacional, as palavras, argumentos e ideias nelas expressos" (MORAES, 1999, p. 3). Neste sentido, analisou-se os conceitos físicos e técnicos dentro dos componentes curriculares, bem como a perspectiva de formação do curso. (1999):

O percurso metodológico se deu a partir de 5 etapas, segundo Moraes

a) Preparação das informações: leitura e organização do PPC, dos documentos oficiais e dos referenciais teóricos;

b) Transformação dos conteúdos em unidades: leitura a partir das temáticas: i) Ensino de Física; ii) Ensino Profissional Integrado ao Ensino Médio e; iii) Ensino de Física e Educação Profissional dentro do curso Técnico em Edificações do IFPA Campus Santarém;

c) Classificação das unidades em categorias: i) Relação/aplicação dos conteúdos e temas da disciplina Física com os conteúdos e temas das disciplinas Técnicas; ii) Projetos Integradores; iii) Perspectiva de formação do Curso Técnico em Edificações;

d) Descrição: explanação teórica dentro de cada unidade, a apresentação dos dados e a discussão dentro das seções;

e) Interpretação: toda compreensão gerada e apresentada a partir das discussões realizadas neste estudo.

Discutindo sobre a relação da Física com as Disciplinas Técnicas, observou-se grandes possibilidades de articulação dos conceitos físicos com os conceitos centrais à área da construção civil. E, que articulação de conhecimentos comuns potencializa a construção da formação do profissional. Entretanto, dentro da formação, é necessário que se tenha como foco não só a potencialização da vertente profissional, mas também da vertente humanasocial-crítica, da vertente científico-tecnológica e da vertente da abertura a continuação da formação em outros níveis de ensino. Ou seja, é necessário que haja uma formação Integral, e que isto esteja pré-estabelecido explicitamente dentro dos componentes curriculares e no perfil de formação do curso.

\section{ENSINO DE FÍSICA NO ENSINO MÉDIO}

A Física do ensino médio se mostra, muitas vezes, como uma disciplina em que são trabalhadas fórmulas e resoluções de problemas de provas. A Vol. 2 (2020) 
maioria dos alunos não consegue contextualizar a física estudada com situações práticas, assim como não consegue manipular as fórmulas apresentadas e resolver os problemas propostos, gerando assim frustações e insatisfação com a Disciplina. Este problema é herança de um ensino tradicional, que vem sendo desenvolvido desde o século XX (CHIQUETTO, 2011).

Até a década de 60, o ensino de Física no ensino básico era fundamentado a partir de livros didáticos, os quais se concentravam sobretudo em conceitos e não apresentavam relações com o cotidiano dos alunos. Estes livros foram importados principalmente dos Estados Unidos (MOREIRA, 2000).

A partir da década de 70, começou-se a introduzir a experimentação no ensino de Física, mas pautada em livros de orientação conceitual, os quais pouco contextualizavam os experimentos com situações do cotidiano dos alunos (MOREIRA, 2000).

A escola do ensino básico da segunda metade do século $X X$ ensinava Física com o objetivo principal de trabalhar a memorização de fórmulas a habilidade de resolver problemas de provas e de vestibulares. A escola deste período pouco se importava com a formação geral do indivíduo a partir do ensino de Física, e sim com uma perspectiva propedêutica de que a física do ensino básico seria complementada em outros níveis, proporcionando somente o suficiente para se obter aprovação nos exames. Essa escola tradicional se propôs a "transmitir conteúdos, deixando em segundo plano a preparação do indivíduo para a vida, uma característica que nosso currículo leva ao extremo, ao negar, inclusive, o relacionamento da Física com a realidade do mundo" (Chiquetto, 2011, p. 06).

A partir do trabalho de Chiquetto (2011), tem-se a seguinte construção, na figura 01, da problemática do Ensino de Física deste período:

FIGURA 01 - Problemas e suas consequências no Ensino de Física, segundo Chiquetto (2011).

\begin{tabular}{|c|c|c|}
\hline & PROBLEMAS/DIFICULDADES & CONSEQUÊNCIAS \\
\hline $\begin{array}{l}\text { ENSINO DE } \\
\text { FÍSICA }\end{array}$ & $\begin{array}{l}\text { Ensino Descontextualizado } \\
\text { Ensino Propedêutico } \\
\text { Ensino mecanizado/instrumental } \\
\text { Foco em resolução de exercícios } \\
\text { Experimentação demonstrativa }\end{array}$ & $\begin{array}{c}\text { Memorização } \\
\text { Aprendizagem não significativa } \\
\text { Desinteresse e insatisfação dos } \\
\text { alunos pela disciplina }\end{array}$ \\
\hline
\end{tabular}

Fonte: Autores

Percebe-se que as principais consequências dos problemas e dificuldades do ensino de Física tradicional, mencionados até aqui, é a característica utilitarista dos conhecimentos de Física, que geram memorização, aprendizagem não significativa e descontextualização, assim como o desinteresse e insatisfação dos alunos com a Disciplina. 
Com esta preocupação, no final do século $X X$, criou-se diretrizes e novos parâmetros curriculares para o ensino básico, assim como para a Física. Estes novos parâmetros e diretrizes têm em vista as problemáticas do ensino tradicional e principalmente a perspectiva interdisciplinar, contextualizada e de formação integral ${ }^{1}$, que deve ocorrer neste nível de ensino.

Menezes (2000, p. 02) fala sobre o ensino de física a partir do que se vislumbra na Lei de Diretrizes e Bases da Educação (LDB/96). O autor entende que além de ensinar a Física (leis, conceitos, princípios científicos), é necessário também que se ensine "os instrumentos gerais que acompanham o aprendizado da física" (o entorno da Ciência: linguagem científica e matemática, contexto histórico, relação com a tecnologia e realidade dos alunos, etc.), os quais estão permeados em outras disciplinas e áreas do conhecimento. Isso permitirá uma aprendizagem em Física consolidada e eficiente para aplicação na vida do aluno, distante isso do ensino tradicional propedêutico, o qual visa complementação de aprendizagens em níveis de ensino posteriores.

Segundo os trabalhos de Moreira (2000), Menezes (2000), Kawamura e Hosoume (2003) e Chiquetto (2011), à luz da LDB/96, as alternativas para superação dos problemas/dificuldades no Ensino de Física e suas consequências mostrados na figura 01, são: a diversificação do ensino, a interdisciplinaridade e a contextualização.

O ensino de Física precisa ser diversificado. Deve haver experimentação e conceituação, contextualização temática com o cotidiano dos alunos e com a história da física, mas nunca deve ser pautado em apenas um desses âmbitos, pois neste ensino se deve prezar pela interação pessoal, pela troca e negociação de significados e conhecimentos. E quando se limita o ensino em apenas um destes âmbitos, também se limita essas práticas no ensino (MOREIRA, 2000).

A ligação do ensino de Física com a tecnologia, também se faz pertinente, pois permite um ensino em que teoria e prática sejam interligadas, proporcionando aos alunos uma visão da ciência no seu cotidiano e, por sua vez, uma aprendizagem significativa (CHIQUETTO, 2011).

Menezes (2000) aponta a motivação e o sentido do ensino de Física nos Parâmetros Curriculares Nacionais - PCN, com a ideia de uma "física como cultura ampla e como cultura prática, assim como a ideia de uma ciência a serviço da construção de visão de mundo e competências humanas mais gerais" (MENEZES, 2000, p. 03).

Indo ao encontro da ideia de Menezes (2000), sobre a perspectiva do ensino de física a partir dos PCN, do início do século XXI, o autor Moreira (2000) aponta para a radicalidade que deve haver na perspectiva do ensino de Física no Ensino Médio:

\footnotetext{
${ }^{1}$ Integral aqui, tido como a concepção de formação baseada nos princípios do Art. 35 da Lei 9394/96 (LDB), que direcionam o ensino médio para além do estágio propedêutico.
} 


\begin{abstract}
Portanto, no ensino médio a perspectiva é também de mudança radical: Física não dogmática, construtivista, para a cidadania, ênfase em modelos, situações reais, elementos próximos, práticos e vivenciais do aluno, do concreto para o abstrato, atualização de conteúdos, física contemporânea (MOREIRA, 2000, p. 05).
\end{abstract}

Percebe-se uma total urgência na mudança de perspectiva do ensino de Física. Esta nova perspectiva se direciona para a construção de conhecimentos que levem o aluno a uma aprendizagem integral, ou seja, científica, tecnológica e cidadã.

Além desse aspecto de contextualização, outro ponto chave abordado pelas diretrizes e parâmetros para o ensino de Física a partir deste período, é a interdisciplinaridade.

A Física deve se articular não somente com as disciplinas da sua área de conhecimento, mas com as demais, pois necessita destes conhecimentos interdisciplinares para a investigação e compreensão, representação e comunicação e contextualização sociocultural de seus próprios fenômenos. Essas dimensões possibilitam organizar o trabalho da disciplina Física de forma integrada com as demais (KAWAMURA e HOSOUME, 2003, p. 12).

De acordo com esta perspectiva, a Física enquanto disciplina, permanece sendo a mesma, mas agora incorporada a conhecimentos de outras disciplinas, que vão proporcionar percursos formativos interdisciplinares e contextualizados com o cotidiano do aluno. Preocupa-se menos com a lista de tópicos ensinada e mais com as competências em Física que se buscam promover.

Dentro desta linha interdisciplinar e contextual, Garcia, Rocha e Costa (2009), criticam os conteúdos de Física que são desenvolvidos de forma estanque pelo ensino tradicional e sugerem, em seu trabalho, conteúdos propostos de forma ampla e articulada entre os próprios conteúdos de física e de outras disciplinas, promovendo interdisciplinaridade e transdisciplinaridade. No quadro 01 abaixo, tem-se a lista de conteúdos de Física proposta pelos autores. 
1. Física: Campo de atuação e método;

2. Medidas. Notação Científica. Sistema Internacional de Unidades;

3. Introdução ao estudo da Mecânica. Leis de Newton;

4. Movimentos uniformes e variáveis;

5. Condições de Equilíbrio;

6. Conservação da Energia;

7. Conservação da quantidade de movimento;

8. Aspectos cinemáticos e dinâmicos da Gravitação Universal;
9. Aspectos cinemáticos e dinâmicos dos meios fluidos;

10. Medidas e efeitos da temperatura;

11. Comportamento térmico dos gases;

12. Energia nas transformações térmicas;

13. Estudo das oscilações mecânicas e eletromagnéticas;

14. Aspectos estáticos e dinâmicos da Eletricidade;

15. Aspectos clássicos

Eletromagnetismo;

16. Tópicos de Física Contemporânea.

Fonte: (Garcia, Rocha e Costa, 2009, p. 140 e 141).

Ao propor estes tópicos, entende-se que esta listagem de conteúdo abarca o básico dos conhecimentos de física para se chegar ao entendimento da realidade do aluno e das tecnologias que o cercam, valorizando a interrelação existente entre os próprios conceitos físicos, entre os conceitos físicos e os conteúdos de outras disciplinas e, o cotidiano de quem irá estudar (GARCIA, ROCHA e COSTA, 2009).

Como visto, a Física tem grande contribuição para a formação científica e cidadã no Ensino Médio. O ensino de Física não deve se basear apenas em resolução de exercícios ou preparação para o Ensino Superior, mas se atentar para a formação científica, para a contextualização dos conceitos em situações do cotidiano dos alunos e para a articulação de aprendizagens com outras disciplinas.

\section{ARCABOUÇO LEGAL E PROPOSTAS DE FORMAÇÃO PARA O ENSINO MÉDIO}

A Lei de Diretrizes e Bases da Educação - LDB (lei no 9394/96) sugere uma formação Integral no Ensino Médio, ou seja, que deixa de funcionar como mera fase intermediária entre o Ensino Fundamental e Superior e como etapa de preparação para o mercado de trabalho. Esta lei indica objetivos mais abrangentes para este nível de formação, os quais perpassam pelo prosseguimento dos estudos, pela preparação básica para o trabalho e a cidadania, pelo aprimoramento como pessoa humana, até a compreensão dos fundamentos científicos-tecnológicos dos processos produtivos.

Art. 35. O ensino médio, etapa final da educação básica, com duração mínima de três anos, terá como finalidades:

I - a consolidação e o aprofundamento dos conhecimentos adquiridos no ensino fundamental, possibilitando o prosseguimento de estudos;

II - a preparação básica para o trabalho e a cidadania do educando, para continuar aprendendo, de modo a ser capaz de se adaptar com 
flexibilidade a novas condições de ocupação ou aperfeiçoamento posteriores;

III - o aprimoramento do educando como pessoa humana, incluindo a formação ética e o desenvolvimento da autonomia intelectual e do pensamento crítico;

IV - a compreensão dos fundamentos científico-tecnológicos dos processos produtivos, relacionando a teoria com a prática, no ensino de cada disciplina (BRASIL, 1996).

Alinhados à LDB, os Parâmetros Curriculares Nacionais para o Ensino Médio - PCNEM, apresentam propostas articuladas de desenvolvimento para esse nível de ensino, com funções equivalentes para todos os educandos:

- a formação da pessoa, de maneira a desenvolver valores e competências necessárias à integração de seu projeto individual ao projeto da sociedade em que se situa;

- o aprimoramento do educando como pessoa humana, incluindo a formação ética e o desenvolvimento da autonomia intelectual e do pensamento crítico;

- a preparação e orientação básica para a sua integração ao mundo do trabalho, com as competências que garantam seu aprimoramento profissional e permitam acompanhar as mudanças que caracterizam a produção no nosso tempo;

- o desenvolvimento das competências para continuar aprendendo, de forma autônoma e crítica, em níveis mais complexos de estudos (BRASIL, 2000, p. 10).

Os PCNEM indicam ainda formas de aprendizagem que o Ensino Médio proporciona aos alunos, as quais são: Aprender a conhecer, aprender a fazer, aprender a viver e aprender a ser.

Aprender a conhecer está relacionado ao "domínio dos próprios instrumentos do conhecimento, considerado como meio e como fim" (p.15), no sentido de "compreender a complexidade do mundo para desenvolver possibilidades pessoais e profissionais de se comunicar" (p.15). Aprender a fazer visa o estímulo de ter a aptidão de desenvolver as teorias aprendidas na prática, seja nos processos essenciais, na tecnologia e no social (BRASIL, 2000).

Aprender a viver trata de desenvolver "o conhecimento do outro e a percepção das interdependências, de modo a permitir a realização de projetos comuns ou a gestão inteligente dos conflitos inevitáveis" (p. 16). E aprender a ser prepara o indivíduo "para elaborar pensamentos autônomos e críticos e para formular os seus próprios juízos de valor, de modo a poder decidir por si mesmo, frente às diferentes circunstâncias da vida" (BRASIL, 2000, p. 16). 
Os PCNEM ainda apontam para a dimensão do prosseguimento dos estudos e preparação para o trabalho, que o Ensino Médio deve proporcionar, entretanto, pautados em conhecimentos científicos significativos aos alunos:

\begin{abstract}
É importante, por exemplo, operar com algoritmos na Matemática ou na Física, mas o estudante precisa entender que, frente àquele algoritmo, está de posse de uma sentença da linguagem matemática, com seleção de léxico e com regras de articulação que geram uma significação e que, portanto, é a leitura e escrita da realidade ou de uma situação desta. Para tanto, deve-se entender que a linguagem verbal se presta à compreensão ou expressão de um comando ou instrução clara, precisa, objetiva (p. 16).

$[\ldots]$

Essa educação geral, que permite buscar informação, gerar informação, usá-la para solucionar problemas concretos na produção de bens ou na gestão e prestação de serviços, é preparação básica para o trabalho. $\mathrm{Na}$ verdade, qualquer competência requerida no exercício profissional, seja ela psicomotora, socio-afetiva ou cognitiva, é um afinamento das competências básicas. Essa educação geral permite a construção de competências que se manifestar-se-ão em habilidades básicas, técnicas ou de gestão (BRASIL, 2000, p. 17).
\end{abstract}

As Orientações Educacionais Complementares aos Parâmetros Curriculares Nacionais para o Ensino Médio ( $\mathrm{PCN}+$ ) apresentam os Temas Estruturadores, os quais têm como objetivo 0 "desenvolvimento das habilidades, competências, conhecimentos, atitudes e valores desejados" para cada disciplina dentro das áreas de conhecimento (BRASIL, 2002 p. 68). Visualizando o caso particular da Física, tem-se os seguintes temas: 1. Movimentos: variações e conservações; 2. Calor, ambiente e usos de energia; 3. Som, imagem e informação; 4. Equipamentos elétricos e telecomunicações; 5. Matéria e radiação; 6 . Universo, Terra e vida.

\title{
Estes Temas Estruturadores de Física servem para:
}

[...] exemplificar, de forma concreta, as possibilidades e os caminhos para o desenvolvimento das competências e habilidades já identificadas. Exemplificam também como reorganizar as áreas tradicionalmente trabalhadas, como Mecânica, Termologia, Eletromagnetismo e Física Moderna, de forma a atribuir-lhes novos sentidos.

Cada um desses temas, contudo, não pode ser compreendido como um tema isolado, já que há inúmeras sobreposições e inter-relações entre os objetos que se pretende estudar. Com certeza, eles somente completam seu sentido por meio de suas interseções e de suas relações com outras áreas do conhecimento (BRASIL, 2002, p. 71). 
Abaixo, no quadro 02, é apresentado o desdobramento dos Temas Estruturadores de Física em Unidades Temáticas.

QUADRO 02: Temas Estruturadores de Física e suas Unidades Temáticas

\begin{tabular}{|c|c|}
\hline TEMAS ESTRUTURADORES & UNIDADES TEMÁTICAS \\
\hline $\begin{array}{l}\text { 1.Movimentos: variações e } \\
\text { conservações }\end{array}$ & $\begin{array}{l}\text { 1. Fenomenologia cotidiana; } \\
\text { 2. Variação e conservação da quantidade de } \\
\text { movimento; } \\
\text { 3. Energia e potência associadas aos movimentos; } \\
\text { 4. Equilíbrios e desequilíbrios. }\end{array}$ \\
\hline $\begin{array}{l}\text { 2.Calor, ambiente e usos de } \\
\text { energia }\end{array}$ & $\begin{array}{l}\text { 1. Fontes e trocas de calor; } \\
\text { 2. Tecnologias que usam calor: motores e } \\
\text { refrigeradores; } \\
\text { 3. O calor na vida e no ambiente } \\
\text { 4. Energia: produção para uso social. }\end{array}$ \\
\hline 3.Som, imagem e informação & $\begin{array}{l}\text { 1. Fontes sonoras; } \\
\text { 2. Formação e detecção de imagens; } \\
\text { 3. Gravação e reprodução de sons e imagens; } \\
\text { 4. Transmissão de sons e imagem. }\end{array}$ \\
\hline $\begin{array}{l}\text { 4.Equipamentos elétricos e } \\
\text { telecomunicações }\end{array}$ & $\begin{array}{l}\text { 1. Aparelhos elétricos; } \\
\text { 2. Motores elétricos; } \\
\text { 3. Geradores; } \\
\text { 4. Emissores e receptores. }\end{array}$ \\
\hline 5. Matéria e radiação & $\begin{array}{l}\text { 1. Matéria e suas propriedades; } \\
\text { 2. Radiações e suas interações; } \\
\text { 3. Energia nuclear e radioatividade; } \\
\text { 4. Eletrônica e informática. }\end{array}$ \\
\hline 6. Universo, Terra e vida & $\begin{array}{l}\text { 1. Terra e sistema solar; } \\
\text { 2. O Universo e sua origem; } \\
\text { 3. Compreensão humana do Universo. }\end{array}$ \\
\hline
\end{tabular}

De acordo com as Orientações Complementares ao PCNEM, estes temas e unidades podem ser trabalhados no Ensino Médio no mais oportuno planejamento de ensino e objetivos que se querem chegar, respondendo às necessidades de cada escola e cada realidade, mantendo-se um tema por semestre letivo, ao longo dos três anos do ensino médio. "Essas escolhas devem ser pautadas por critérios claros e compartilhados com o conjunto dos professores" (BRASIL, 2002, p.79). 
No entanto, todo este desenho dos Temas Estruturadores foi concebido à luz da LDB de 1996. A partir das Diretrizes Curriculares Nacionais para o Ensino Médio, materializadas na Resolução CNE no 2 de 2012, tem-se um novo desenho dos Componentes Curriculares, em novas áreas de conhecimento, e uma perspectiva de ensino direcionada para integração profissional. A partir de 2017, tem-se como referência a Lei ํo13.415/17, conhecida como a Lei da Reforma do Ensino Médio, que faz alterações na Lei n $\cong 9.394 / 96$ e na Resolução CNE no 2 de 2012, quanto à organização de componentes curriculares, assim como à orientações para a construção do Currículo, as quais são apresentadas na Base Nacional Comum Curricular para o Ensino Médio - BNCC.

No quadro 03 abaixo, é apresentado a descrição da organização curricular em cada um dos documentos mencionados no parágrafo anterior.

QUADRO 03: Organização Curricular do Ensino Médio segundo arcabouço legal

\begin{tabular}{|c|c|}
\hline $\begin{array}{l}\text { RESOLUÇÃO CEB № } \\
3 / 1998 \text { - Institui as } \\
\text { Diretrizes Curriculares } \\
\text { Nacionais para o } \\
\text { Ensino Médio. }\end{array}$ & $\begin{array}{l}\text { Art. } 10 \text { A base nacional comum dos currículos do ensino } \\
\text { médio será organizada em áreas de conhecimento, a saber: } \\
\text { I - Linguagens, Códigos e suas Tecnologias [...]; } \\
\text { II - Ciências da Natureza, Matemática e suas Tecnologias [...]; } \\
\text { III - Ciências Humanas e suas Tecnologias [...] (p. 04). }\end{array}$ \\
\hline $\begin{array}{c}\text { RESOLUÇÃO CNE № } \\
\text { 2/2012 - Define } \\
\text { Diretrizes Curriculares } \\
\text { Nacionais para o Ensino } \\
\text { Médio. }\end{array}$ & $\begin{array}{l}\text { Art. } 7^{0} \text { A organização curricular do Ensino Médio tem uma } \\
\text { base nacional comum e uma parte diversificada que não } \\
\text { devem constituir blocos distintos, mas um todo integrado, de } \\
\text { modo a garantir tanto conhecimentos e saberes comuns } \\
\text { necessários a todos os estudantes, quanto uma formação } \\
\text { que considere a diversidade e as características locais e } \\
\text { especificidades regionais. } \\
\text { Art. 8o O currículo é organizado em áreas de conhecimento, a } \\
\text { saber: } \\
\text { I - Linguagens; } \\
\text { II - Matemática; } \\
\text { III - Ciências da Natureza; } \\
\text { IV - Ciências Humanas. (p. 02) }\end{array}$ \\
\hline $\begin{array}{l}\text { LEI № } 13.415 / 2017 \text { - } \\
\text { Altera a Lei noo } \\
9.394 / 1996, \text { que } \\
\text { estabelece as diretrizes } \\
\text { e bases da educação } \\
\text { nacional. }\end{array}$ & $\begin{array}{l}\text { Art. 3․ A Lei no 9.394, de } 20 \text { de dezembro de } 1996 \text {, passa a } \\
\text { vigorar acrescida do seguinte art. 35-A: } \\
\text { Art. 35-A. A Base Nacional Comum Curricular definirá direitos } \\
\text { e objetivos de aprendizagem do ensino médio, conforme } \\
\text { diretrizes do Conselho Nacional de Educação, nas seguintes } \\
\text { áreas do conhecimento. } \\
\text { I - Linguagens e suas tecnologias; }\end{array}$ \\
\hline
\end{tabular}




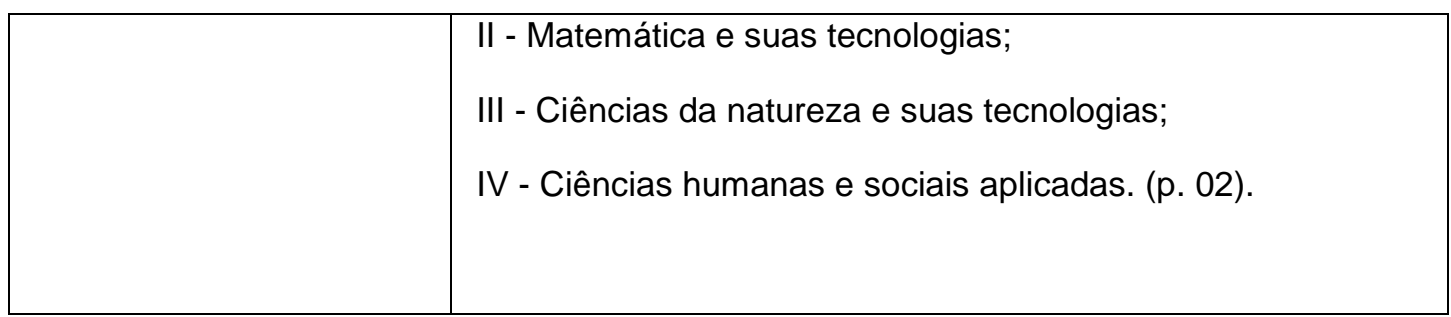

Fonte: Autores

Na Resolução CEB № 3/1998 a Física é componente curricular da área de conhecimento Ciências da Natureza, Matemática e suas tecnologias, juntamente com as disciplinas Matemática, Química e Biologia. Esta proposta de currículo é construída a partir das perspectivas de interdisciplinaridade, contextualização e formação integral oriunda da LDB/96 (BRASIL, 1998).

Já na Resolução CNE № 2/2012, a Física está presente na área de conhecimento Ciências da Natureza juntamente com a Química e Biologia. Nesta, a Matemática se desmembra e forma uma outra área de conhecimento. Esta proposta de currículo é concebida com base na ideia de diálogo entre a educação e as questões advindas do mercado de trabalho, da ciência, da tecnologia e da cultura, tendo como premissa para o currículo uma base nacional comum e uma parte diversificada, que não devem constituir blocos distintos (BRASIL, 2012a).

Na LEI № 13.415/2017, a Física está inclusa na área de conhecimento Ciências da natureza e suas tecnologias, novamente junto com a Química e Biologia. E, segundo esta lei, a prioridade é a articulação entre componentes curriculares de mesma área e de áreas distintas. Essa articulação ocorre a partir do contexto sócio-histórico-econômico e por meio de instrumentos tecnológicos. Tem-se como premissa o currículo construído a partir de uma base nacional comum e de uma parte diversificada, aproximando a formação científica da profissional (BRASIL, 2017).

Ramos e Heinsfeld (2017), fazem uma comparação em relação aos enunciados do artigo 36 da LDB/96 com sua modificação enunciada na Lei №13.415/17. Esta comparação é apresentada no quadro 04, a seguir: 


\begin{tabular}{|c|c|}
\hline Art. 36, Lei no 9.394/1996 & Art. 36, Lei no 13.415/2017 \\
\hline $\begin{array}{l}\text { Art. 36. O currículo do ensino médio } \\
\text { observará o disposto na Seção I deste } \\
\text { Capítulo e as seguintes diretrizes: } \\
\text { I - destacará a educação tecnológica } \\
\text { básica, a compreensão do significado da } \\
\text { ciência, das letras e das artes; o processo } \\
\text { histórico de transformação da sociedade e } \\
\text { da cultura; a língua portuguesa como } \\
\text { instrumento de comunicação, acesso ao } \\
\text { conhecimento e exercício da cidadania; } \\
\text { II - adotará metodologias de ensino e de } \\
\text { avaliação que estimulem a iniciativa dos } \\
\text { estudantes [...] }\end{array}$ & $\begin{array}{l}\text { Art. 36. O currículo do ensino médio será } \\
\text { composto pela Base Nacional Comum } \\
\text { Curricular e por itinerários formativos, que } \\
\text { deverão ser organizados por meio da oferta } \\
\text { de diferentes arranjos curriculares, } \\
\text { conforme a relevância para o contexto local } \\
\text { e a possibilidade dos sistemas de ensino, a } \\
\text { saber: } \\
\text { I - linguagens e suas tecnologias; } \\
\text { II - matemática e suas tecnologias; } \\
\text { III - ciências da natureza e suas } \\
\text { tecnologias; } \\
\text { IV - ciências humanas e sociais aplicadas; } \\
\text { V-formacão técnica e profissional. }\end{array}$ \\
\hline
\end{tabular}

Fonte: (RAMOS e HEINSFELD, 2017) com modificações.

Ramos e Heinsfeld (2017) questionam a perspectiva utilitarista do ensino médio apresentada pela lei $\mathrm{n}^{\circ} 13.415 / 17$, "em que há o favorecimento de objetivos que endossem certos cenários sociais desejados" (p.11), favorecendo o ensino propedêutico/profissionalizante utilitarista em detrimento de uma proposta de formação humana mais completa, a qual é oferecida pela Lei no 9.394/1996.

Nesse caso, busca-se conhecimentos que vão ao encontro do ideal de modernização tecnológica e progresso da industrialização. Por isso são privilegiadas determinadas áreas em detrimentos de outras e, com isso, não há a integralidade da formação nos âmbitos social-humano, acadêmico e profissional (RAMOS E HEINSFELD, 2017).

A autora Ramos (2018) critica essa tendência de privilegiar os itinerários formativos, em benefício da formação técnica profissional, característica da Lei ํo 13.415/2017. Não se pode sacrificar a formação geral básica para substituir ou intensificar itinerários profissionalizantes. Gera-se com isso, uma fragmentação formativa do Ensino Médio.

O fruto deste novo ideário para a formação do ensino médio, o qual orienta a construção de itinerários formativos flexíveis, originado pela Lei de Reforma do Ensino Médio, foi a Base Nacional Comum Curricular, que define competências específicas para cada área do conhecimento. Atrelado a essas competências, tem-se habilidades a serem desenvolvidas em cada etapa de formação (BRASIL, 2018).

$\mathrm{Na}$ área de Ciências da Natureza e suas Tecnologias, é proposto que os estudantes possam "construir e utilizar conhecimentos específicos da área para argumentar, propor soluções e enfrentar desafios locais e/ou globais, relativos 
às condições de vida e ao ambiente" (BRASIL, 2018, p. 470). Para esta área de conhecimento, que a Física se faz presente juntamente com a Química e Biologia, tem-se as seguintes competências esperadas:

1. Analisar fenômenos naturais e processos tecnológicos, com base nas relações entre matéria e energia, para propor ações individuais e coletivas que aperfeiçoem processos produtivos, minimizem impactos socioambientais e melhorem as condições de vida em âmbito local, regional e/ou global.

2. Construir e utilizar interpretações sobre a dinâmica da Vida, da Terra e do Cosmos para elaborar argumentos, realizar previsões sobre o funcionamento e a evolução dos seres vivos e do Universo, e fundamentar decisões éticas e responsáveis.

3. Analisar situações-problema e avaliar aplicações do conhecimento científico e tecnológico e suas implicações no mundo, utilizando procedimentos e linguagens próprios das Ciências da Natureza, para propor soluções que considerem demandas locais, regionais e/ou globais, e comunicar suas descobertas e conclusões a públicos variados, em diversos contextos e por meio de diferentes mídias e tecnologias digitais de informação e comunicação (TDIC) (BRASIL, 2018, p. 539).

A construção das competências pode seguir itinerários formativos compatíveis com as demandas (sociais, culturais, políticas) dos centros de ensino no qual irão se desenvolver. Ocorrerá de forma transdisciplinar, com as demais disciplinas da grande área do conhecimento e poderão ou não ser utilizadas, a partir do que se prioriza na formação (BRASIL, 2018).

Entretanto, entende-se que quando há priorização de alguns itinerários formativos em detrimento de outros, há a precarização da formação, pois se prejudica a formação integral pretendida com o Ensino Médio.

\section{A FORMAÇÃO DE FÍSICA NO CURSO TÉCNICO EM EDIFICAÇÕES INTEGRADO AO ENSINO MÉDIO DO IFPA CAMPUS SANTARÉM}

A educação profissional e tecnológica, de acordo com a LDB, faz parte dos diferentes níveis e modalidades de Educação e das distintas dimensões do trabalho, da ciência e da tecnologia. Os cursos, dentro dessa modalidade, poderão ser organizados por eixos tecnológicos, possibilitando a construção de diferentes itinerários formativos, o que vai ao encontro dos pressupostos mencionados na BNCC.

De acordo com o artigo 36 da Lei 9.394/96, a educação profissional técnica de nível médio será desenvolvida nas seguintes formas: 
I - articulada com o ensino médio; (Incluído pela Lei no 11.741, de 2008)

II - subsequente, em cursos destinados a quem já tenha concluído o ensino médio. (Incluído pela Lei no 11.741, de 2008).

$[\ldots]$

Art. 36-C. A educação profissional técnica de nível médio articulada, prevista no inciso I do caput do art. 36-B desta Lei, será desenvolvida de forma: (Incluído pela Lei no 11.741 , de 2008)

I - integrada, oferecida somente a quem já tenha concluído o ensino fundamental, sendo o curso planejado de modo a conduzir o aluno à habilitação profissional técnica de nível médio, na mesma instituição de ensino, efetuando-se matrícula única para cada aluno; (Incluído pela Lei $n=11.741$, de 2008)

II - concomitante, oferecida a quem ingresse no ensino médio ou já o esteja cursando, efetuando-se matrículas distintas para cada curso, e podendo ocorrer: (Incluído pela Lei $\mathrm{n}^{\circ} \mathbf{1 1 . 7 4 1}$, de 2008) (BRASIL, 1996).

O curso Técnico em Edificações do IFPA Campus Santarém ${ }^{2}$ é desenvolvido na modalidade Integrada ao Ensino Médio. Ou seja, o egresso deste curso dispõe de formação do Ensino Médio articulada com a formação técnica profissional, tendo seu perfil de formação e seu itinerário formativo integrados em um único Projeto Pedagógico.

A formação no Ensino Médio de forma Integrada, segundo Ciavatta (2005), direciona o aluno participante para uma formação humana geral (não genérica), buscando-se conhecimentos técnico-científicos, os quais possam ser apropriados em seus contextos histórico-sociais. "Sugere superar o ser humano dividido historicamente pela divisão do trabalho entre a ação de executar e a ação de pensar, dirigir ou planejar" (CIAVATTA, 2005, p. 85).

Esta concepção de formação integrada está expressa em uma origem de educação socialista, que de acordo com Ciavatta, possui cunho omnilateral", "no sentido de formar o ser humano na sua integridade física, mental, cultural, política, científico-tecnológica” (2005, p. 86).

Neste contexto, Ramos (2005) discute pressupostos de possibilidades e desafios na organização do currículo de ensino médio integrado à Educação Profissional, de forma que:

\footnotetext{
${ }^{2}$ Este curso está disponível no IFPA/Santarém desde a fundação do campus, no ano de 2010. Neste percurso, passou por várias atualizações em seu PPC, as quais foram construídas por docentes e equipe pedagógica do próprio campus e, a partir de demandas locais.

${ }^{3}$ Omnilateral, vem da ideia de Karl Marx sobre educação, em que a formação humana deve ser oposta à unilateral, a qual provoca trabalho alienado - praticado pela divisão social do trabalho -, exclusivo desenvolvimento intelectual de elites burguesas, individualismo e limitação social e intelectual do homem frente a capitalismo (http://www.sites.epsjv.fiocruz.br/dicionario/verbetes/omn.html).
} 
a) conceba o sujeito como ser histórico-social concreto, capaz de transformar a realidade em que vive;

b) vise a formação humana como síntese de formação básica e formação para o trabalho;

c) tenha o trabalho como princípio educativo no sentido de que o trabalho permite, concretamente, a compreensão do significado econômico, social, histórico, político e cultural das ciências e das artes;

d) seja baseado numa epistemologia que considere a unidade de conhecimentos gerais e conhecimentos específicos e numa metodologia que permita a identificação das especificidades desses conhecimentos quanto à sua historicidade, finalidades e potencialidades;

e) seja baseado numa pedagogia que vise à construção conjunta de conhecimentos gerais e específicos, no sentido de que os primeiros fundamentam os segundos e esses evidenciam o caráter produtivo concreto dos primeiros;

f) seja centrado nos fundamentos das diferentes técnicas que caracterizam o processo de trabalho moderno, tendo como eixos o trabalho, a ciência e a cultura (RAMOS, 2005, p. 108).

O ensino médio integrado à educação profissional deve ter como objetivo central, de acordo com Ramos (2005), a formação integral de pessoas, que compreendam sua realidade, atuando de forma protagonista como profissionais, e não meramente como técnicos.

\subsection{CURRÍCULO DO CURSO TÉCNICO EM EDIFICAÇÕES}

O Curso Técnico em Edificações, atendendo ao disposto no Catálogo Nacional dos Cursos Técnicos, e às demandas profissionais da região à qual está inserido, enuncia uma preparação do profissional para:

[...] projetar e executar obras de acordo com a legislação especifica, propondo alternativas do uso de técnicas e materiais de construção, elaborando o planejamento e o orçamento necessários à escolha da melhor solução a ser adotada na ocupação do solo, tendo por premissa o respeito à preservação ambiental (PPC, 2016).

Segundo o PPC do curso, fundamentado pelas Diretrizes Curriculares Nacionais - DCN - para a Educação Profissional Técnica de Nível Médio (Parecer no 06 CNE/CBN 2012), a organização curricular deste curso busca contemplar "trajetórias dos itinerários formativos e estabelecer exigências 
profissionais que direcionem a ação educativa das instituições e dos sistemas de ensino" (PPC, 2016, p. 12). O curso está organizado de modo que leve em consideração "os conhecimentos trazidos das experiências dos alunos/as, que articule a formação humana e profissional para que eles possam compreender o mundo que os cerca e atuarem sobre ele" (PPC, 2016, p. 15).

Esta organização se alinha aos pressupostos para a formação técnica integrada ao ensino médio propostos por Ramos (2005). Além disso, pode-se comparar essa tendência do PPC do curso às finalidades esperadas para 0 ensino médio, como um todo, levantadas no artigo 35 da LDB/96, assim como às aprendizagens prescritas pelos PCNEM (aprender a conhecer, a fazer, a viver e ser).

Analisando-se o perfil de formação do Curso Técnico em Edificações descrito em seu PPC, observa-se a estrutura formativa do curso indicando atividades curriculares, segundo a sua natureza acadêmica, em Componentes Curriculares de formação Básica e de formação Específica, da seguinte forma:

Os componentes curriculares de formação básica irão fundamentar os conhecimentos da área e contribuirão como ferramentas e apoio no entendimento e aplicação dos conhecimentos técnicos científicos.

Os componentes curriculares específicos visam desenvolver um conjunto de habilidades e competências necessárias para 0 desenvolvimento das atividades específicas do profissional da área (PPC, 2016, p. 16).

De acordo com as áreas do conhecimento previstas na Lei 13.415/2017, percebe-se que há construção de uma base comum, com a utilização dos componentes curriculares das áreas I, II, III e IV, assim como há a promoção de componentes curriculares específicos, que se enquadram na área de conhecimento $\mathrm{V}$. Mas, ao contrário do que se verifica nas diretrizes da referida Lei, não há a possibilidade de privilegiar algum dos componentes básicos, pois se entende neste curso que todos são imprescindíveis para a formação que se pretende oferecer: a formação humana integral (PPC, 2016).

Segundo o PPC do curso, a estruturação da Matriz Curricular tem por base as competências e habilidades necessárias ao mundo do trabalho desta área, visando a atender os diversos setores da economia que venham a precisar de um profissional de Edificações (PPC, 2016).

Entretanto, o que se analisa da descrição dos componentes curriculares é que os de formação básica servem apenas para dar suporte, no sentido de oferecer entendimento e aplicação aos de formação específica. Não é citado, na descrição dos componentes, a vertente de formação integral (humana, científica-tecnológica e profissional) dos componentes de formação básica, evidenciados por Ciavatta (2005) e Ramos (2005).

Outro aspecto que se observa no PPC é relacionado ao ementário das disciplinas de formação básica. E nesta oportunidade, analisa-se o caso das 
disciplinas de Física. Diferentemente do que é apresentado nas Orientações Complementares ao PCNEM, no PPC do curso os conteúdos são apresentados em temas gerais. Nos PCNEM's, eles são apresentados em forma de temas que estruturam o currículo da disciplina, e ainda em unidades temáticas, as quais explicitam detalhadamente o que se pode explorar de conceitos dentro de cada tópico.

No quadro 05 abaixo, mostra-se os conteúdos que são trabalhados nas disciplinas de Física, segundo os seus ementários.

QUADRO 05: Conteúdos de Física do Curso Técnico em Edificações

\begin{tabular}{|c|c|c|}
\hline Física I & Física II & Física III \\
\hline $\begin{array}{l}\text { Breve } \begin{array}{c}\text { introdução à Álgebra } \\
\text { linear: Vetores e }\end{array} \text { suas } \\
\text { aplicações; Cinemática e suas } \\
\text { aplicações; Dinâmica e suas } \\
\text { aplicações; Estática e suas } \\
\text { aplicações; Trabalho e Energia } \\
\text { Mecânica e suas aplicações; } \\
\text { Momento Linear e suas } \\
\text { aplicações; Momento Angular e } \\
\text { suas aplicações; Introdução à } \\
\text { mecânica celeste; Fluido } \\
\text { mecânica; Atividades } \\
\text { experimentais; Breve introdução } \\
\text { ao cálculo aplicado à Física. }\end{array}$ & $\begin{array}{l}\text { Termodinâmica; } \\
\text { Oscilações; Ondulatória; } \\
\text { Acústica; Leis de } \\
\text { conservação; } \\
\text { geométrica e } \text { Oficica } \\
\text { Radiação; Atividades } \\
\text { experimentais }\end{array}$ & 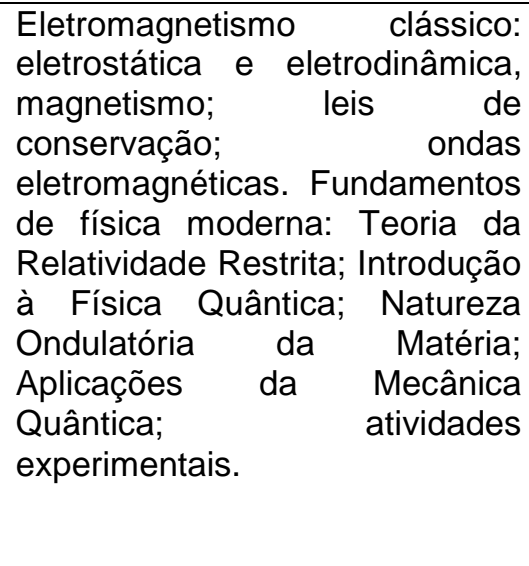 \\
\hline
\end{tabular}

Fonte: (PPC, 2016)

Percebe-se que os conteúdos estão dispostos no ementário das disciplinas, próximo à ideia de Garcia, Rocha e Costa (2009), os quais são organizados a partir de tópicos gerais que abarcam implicitamente os conceitos físicos de tal tópico.

Apesar da proposta de generalização dos conteúdos em tópicos buscar a possibilidade de uma abordagem interdisciplinar, isso dificulta visualizar 0 grau de relação dos temas e conteúdo de Física, com os temas e conteúdo das demais disciplinas, principalmente se tratando das disciplinas Técnicas. $\mathrm{Ou}$ seja, o que é colocado como opção para se desenhar a formação com uma perspectiva interdisciplinar é inviabilizado pela falta de visualização dos conteúdos dentro das temáticas, que podem se relacionar. Entende-se então, que a proposta se torna contraditória.

Esta falta de visualização gera, ainda, impossibilidade de utilização de conceitos que servem como base conceitual para construção de conhecimentos dentro de temas de maior complexidade, contextualização e aplicabilidade. 


\subsubsection{Relação/Aplicação dos temas e conteúdo da disciplina Física com as disciplinas Específicas}

O curso Técnico em edificações dispõe de 17 disciplinas Técnicas, divididas nos três anos de formação, sendo 06 no primeiro ano, 06 no segundo ano e 05 no terceiro ano. Destas, 09 disciplinas apresentam relação ou fazem aplicação de temas e conteúdos físicos, que são trabalhados nas disciplinas de Física durante o curso.

No quadro 06, a seguir, são apresentadas as disciplinas Técnicas que possuem relação com as disciplinas de Física, o ano em que elas são desenvolvidas no curso, e qual a disciplina de Física que elas se articulam.

QUADRO 06. Disciplinas Técnicas que apresentam relação com a Física

\begin{tabular}{|c|c|c|}
\hline \multirow{2}{*}{ ANO } & DISCIPLINA & $\begin{array}{c}\text { FISICA QUE SE } \\
\text { RELACIONA/APLICA }\end{array}$ \\
\hline \multirow{2}{*}{$1^{\circ}$} & Obras Geotécnicas & I \\
\cline { 2 - 3 } & Fundamentos de Estruturas & I \\
\hline \multirow{2}{*}{$2^{\circ}$} & Topografia Aplicada & I, II e III \\
\cline { 2 - 3 } & Instalações Prediais & I \\
\cline { 2 - 3 } & Introdução às estruturas de Madeira & II e III \\
\cline { 2 - 3 } & Higiene e Segurança do trabalho & I \\
\hline \multirow{3}{*}{$3^{\circ}$} & Tecnologia dos Materiais & I I e III \\
\cline { 2 - 3 } & Estrutura de Madeira & \\
\cline { 2 - 3 } & Patologia das Construções & \\
\hline
\end{tabular}

Fonte: (PPC, 2016)

Observamos que quase todas as disciplinas Técnicas apresentam aplicabilidade ou relação com os conceitos de 'Física l', principalmente se tratando dos tópicos 'Fluído Mecânica' e 'Estática e suas Aplicações'. São temas recorrentes dentro da Construção Civil, os quais são relacionados a conceitos físicos, como força, equilíbrio, densidade, entre outros.

Percebe-se também que há, em grande parte, concomitância das disciplinas Técnicas em relação às disciplinas de Física, ao ano em que elas são desenvolvidas, haja vista que os conceitos e as disciplinas afins são Vol. 2 (2020) 
trabalhados no mesmo ano ou em anos posteriores. Salvo duas disciplinas, 'Instalações Prediais' e 'Higiene e Segurança no Trabalho', as quais são abordadas no segundo ano e requerem conhecimentos físicos que são abordados na 'Física III'.

Isso é extremamente importante para a aplicabilidade do conteúdo de Física no conteúdo técnico, e também para a ideia de construção de conhecimentos prévios. Outro aspecto é a possibilidade de desenvolvimento de atividades didáticas diversificadas e interdisciplinares, quando as disciplinas se relacionam no mesmo ano. Estas possibilidades são mencionadas nos trabalhos de Moreira (2000), Menezes (2000), Kawamura e Hosoume (2003) e Chiquetto (2011), quando estes autores falam sobre alternativas para superação dos problemas e dificuldades do ensino de física tradicional do século XX.

Entretanto, faz-se uma crítica à disposição/descrição dos conteúdos de Física em seus ementários, haja vista que não há apresentação de unidades temáticas explícitas. Isso dificulta a visualização da relação Física/Disciplina Técnica por parte dos docentes envolvidos no desenvolvimento das disciplinas. Os PCNEM fazem essa orientação, quanto à preparação do currículo de forma conjunta pelos professores, em que atendam critérios e objetivos claros e compartilhados, buscando desenvolver nos alunos a representação e comunicação, a investigação e compreensão e a contextualização sociocultural.

Vale ressaltar, que nesta pesquisa, um dos autores possui formação nas duas áreas, em Física e em Edificações. E a visualização das relações existentes perpassaram pelas experiências e significados guiados pelo olhar do autor acerca dos conteúdos descritos, das duas áreas, nos seus componentes curriculares.

\subsubsection{Projeto Integrador}

O IFPA Campus Santarém, tem em sua matriz curricular 0 desenvolvimento dos Projetos Integradores. Neste sentido o discente do Curso Técnico em Edificações deverá participar de no mínimo um projeto integrador durante o curso. Este projeto, está expresso na matriz curricular, como uma atividade desenvolvida durante o terceiro ano, e pode ter a abordagem de ensino, pesquisa ou extensão. Os projetos são desenvolvidos pelos discentes, sob a orientação dos professores do curso, e seus resultados são socializados na Semana Integrada dos Cursos do IFPA (PPC, 2016).

O PPC do curso apresenta a seguinte descrição sobre os projetos integradores:

Os Projetos Integradores têm como premissa a interdisciplinaridade, ao relacionar os conhecimentos profissionais com a formação geral, a 
inovação, a iniciação cientifica, a iniciativa, a criatividade e o empreendedorismo (PPC, 2016, p. 51).

Observa-se que há uma proposta de relacionamento entre os componentes curriculares de formação básica e específicos, a partir de um projeto que possui tema integrador, favorecendo a perspectiva interdisciplinar, a contextualização de conceitos e a aplicação de conhecimentos na prática, envolvendo um problema do cotidiano dos alunos. Entretanto, a proposta é executada em apenas um dos anos do desenvolvimento do curso, o que não demostra uma constância da relação entre componentes curriculares de formação básica e específica.

\subsubsection{Perspectiva de formação do curso Técnico em Edificações}

O Curso Técnico em Edificações busca formar profissionais com um perfil de formação que atenda a três premissas básicas: "formação científicotecnológico-humanística sólida, flexibilidade para as mudanças e educação continuada para atuar em várias áreas dentro da construção civil" (PPC, 2016, p. 15). Observa-se também no PPC do curso, o objetivo de formar profissionais que primem pelo controle de qualidade, bem como sejam inovadores, empreendedores e líderes, buscando sempre a preservação ambiental, a utilização racional dos recursos naturais e o desenvolvimento sustentável. Busca-se ainda formar pessoas capazes de lidar com o avanço da ciência e da tecnologia e, delas participarem de forma proativa (PPC, 2016).

As DCN para a Educação Profissional Técnica de Nível Médio, preconizam que os cursos técnicos devem "ser organizados por eixos tecnológicos, possibilitando itinerários formativos flexíveis, diversificados e atualizados, segundo interesses dos sujeitos e possibilidades das instituições educacionais [...]" (BRASIL, 2012b, p. 01).

Os pressupostos do perfil de formação descritos no PPC e sugeridos pelas DCN para Educação Profissional se alinham quanto aos seus objetivos. Entretanto, quando se analisa as finalidades da formação oferecida pelo curso, observa-se que o perfil de formação se limita a explicitar apenas a vertente profissional, como se observa a seguir:

Ao final do curso o aluno será capaz de:

- Planejar a execução e a elaboração de orçamento de obras.

- Desenvolver projetos e pesquisas tecnológicas na área de edificações.

- Coordenar a execução de serviços de manutenção de equipamentos e de instalações em edificações. 
- Conduzir a execução técnica dos trabalhos de sua especialidade, como por exemplo, a utilização da ferramenta CAD (PPC, 2016, p. 16).

No perfil de formação do Curso, não estão explícitas as finalidades das vertentes científica-tecnológica e humana, discutidas por Ciavatta (2005) e Ramos (2005), assim como das vertentes da formação ética e intelectual, da formação pessoal do indivíduo e do desenvolvimento de competências para a continuidade da formação para níveis posteriores, propostos pelos PCNEM e pelo próprio PPC.

Percebe-se ainda, no PPC do curso, que não há a construção dos componentes curriculares de acordo com esta perspectiva. Observa-se, analisando as disciplinas de Física (representando a formação básica) e as disciplinas Técnicas, que não há na descrição de suas ementas, conteúdos e temas que sejam capazes de alcançar as finalidades de todas as vertentes esperadas para o ensino médio.

Não há, de forma explicita, propostas de relação de conteúdos que sejam capazes de lidar com a formação profissional - na perspectiva de produção de conhecimentos científicos e tecnológicos integrados -, que direcione o educando a uma formação humanística Integral, na qual os conhecimentos partam da teoria tendo a prática como norte, oportunizando a transformação de sua realidade social. Essa transformação social e contextual, se dá a partir da sua prática profissional e de suas habilidades científica, tecnológica e humana, segundo Ciavatta (2005) e Ramos (2005).

Ou seja, a formação deve ter como objetivo e justificativa todos os âmbitos de uma formação humanística integral, além de ser concebida à luz da perspectiva interdisciplinar. Isso se materializa a partir da construção do itinerário formativo dos componentes curriculares e do perfil de formação, os quais são descritos no PPC do curso.

Precisa-se, além de detalhar as finalidades de formação profissional, a partir dos Componentes Curriculares Específicos e o perfil de formação, explicitar também as finalidades de formação científica, tecnológica, cidadã e humana, a partir dos Componentes Curriculares de Formação Básica e do perfil de formação. Além disso, precisa-se ter Componentes Curriculares Integradores, ou que direcione à integração dos Específicos e de Formação Básica, em todos os anos do período de formação do curso.

\section{CONSIDERAÇÕES FINAIS}

O Ensino de Física possui grande contribuição para a formação científica e cidadã no Ensino Médio. É necessário que este vá além da concepção propedêutica e que se direcione para uma perspectiva de formação científica, interdisciplinar, contextualizada e articulada com conhecimentos de outras disciplinas. 
Neste trabalho, avaliaram-se as relações existentes entre a Disciplina Física e as Disciplinas Técnicas presentes no curso Técnico em Edificações do IFPA Campus Santarém, além do seu perfil de formação esperado. Esta análise se deu a partir do PPC do curso, de documentos oficiais que orientam a formação no Ensino Médio e, a partir do debate teórico com referenciais que versam sobre estas temáticas.

Observou-se, neste trabalho, que o campo científico da Física abrange grande parte dos conceitos empregados e contextualizados dentro da área da Construção Civil. Os conceitos Físicos são imprescindíveis para o percurso formativo das disciplinas Técnicas do curso Técnico em Edificações. Eles dão base aos significados e aprendizagens vivenciados nas disciplinas Técnicas, e agregam habilidades à formação profissional, tecnológica e científica, que é objetivado pelos Componentes Curriculares Específicos, de acordo com o PPC do curso.

Por isso, o Ensino de Física neste curso deve ser trabalhado de forma diversificada, contextualizada e interdisciplinar. Os seus tópicos devem ser descritos minunciosamente, para que a visualização da relação interdisciplinar, principalmente com as disciplinas Técnicas seja favorecida. O planejamento, deste ensino, deve ser pensado de forma conjunta pelos professores, visualizando esta relação, bem como a realidade em volta ao curso e seu perfil de formação.

Outro aspecto observado neste trabalho é a ausência de componentes curriculares integradores, ou seja, que façam a ligação entre os componentes formação básica e os específicos, possibilitando assim uma formação profissional interdisciplinar e contextualizada. E há a necessidade que esses componentes curriculares integradores, possam ser desenvolvidos em todos os anos do curso.

Percebeu-se com este trabalho que no perfil de formação do egresso deste curso é bastante evidenciada a vertente profissional. Entretanto, necessita-se que a elaboração dos pressupostos e finalidades da formação, caminhem ao encontro de outras vertentes pretendidas no ensino médio profissional. E isso precisa estar presente explicitamente no perfil de formação e descritas no documento norteador do curso.

Espera-se, como formação profissional integrada ao Ensino Médio, que esta seja Integral, ou seja, forme o educando para o prosseguimento da formação em níveis mais elevados, e nos âmbitos profissional, crítico-científico e social-humano.

\section{REFERÊNCIAS}

BRASIL, Ministério da Educação, Conselho Nacional de Educação, Câmara de Educação Básica. (2012a). Resolução № 2, 30 de janeiro de 2012. Define Diretrizes Curriculares Nacionais para o Ensino Médio. Diário Oficial da União. Disponível em: 
http://portal.mec.gov.br/index.php?option=com_docman\&view=download\&alias $=9864$-rceb002-12\&category_slug=janeiro-2012-pdf\&ltemid=30192. Acesso em: 14 jul. 2019.

BRASIL. Lei n. 9.394, de 20 de dezembro de 1996. Estabelece as diretrizes e bases da educação nacional. Brasília, DF, 1996.

BRASIL. Lei no 13.145, de 16 de fevereiro de 2017. Altera a Leis $n^{\circ}$ 9.394, de 20 de dezembro de 1996, que estabelece as diretrizes e bases da educação nacional.

BRASIL. Ministério da Educação. Base Nacional Comum Curricular. Brasília, DF: MEC, 2018. Disponível em:

http://portal.mec.gov.br/index.php?option=com_docman\&view=download\&alias $=85121$-bncc-ensino-medio\&category_slug=abril-2018-pdf\&ltemid=30192.

Acesso em: 22 nov. 2019.

BRASIL. Ministério da Educação. PCN+ Ensino Médio: Orientações

Educacionais Complementares aos Parâmetros Curriculares Nacionais: Ciências da Natureza Matemática e suas Tecnologias: Física. Brasília: MEC, 2002. Disponível em http://portal.mec.gov.br/seb/arquivos/pdf/CienciasNatureza.pdf. Acesso em: 14 jul. 2019.

BRASIL. Parâmetros Curriculares Nacionais. ensino médio. Ministério da Educação, 2000. Disponível em: http://bit.ly/2DCWvdc. Acesso em: 14 jul. 2019.

BRASIL. Resolução CNE/CEB n. 03 de 26 de junho de 1998. Institui as Diretrizes Curriculares Nacionais para o Ensino Médio. Disponível em: http://portal.mec.gov.br/cne/arquivos/pdf/rceb03_98.pdf. Acesso em: 11 jan. 2020.

BRASIL. Resolução № 6, de 20 de setembro de 2012b. Define Diretrizes Curriculares Nacionais para a Educação Profissional Técnica de Nível Médio. MEC.

CHIQUETTO, Marcos José. O currículo de física do ensino médio no Brasil: discussão retrospectiva. Revista e-curriculum, v. 7, n. 1, 2011. Disponível em: https://revistas.pucsp.br/curriculum/article/view/5646/3990. Acesso em: 14 jul. 2019.

CIAVATTA, M. A formação integrada: a escola e o trabalho como lugares de memória e de identidade. In: FRIGOTTO, G.; CIAVATTA, M.; RAMOS, M. (Org.). Ensino Médio Integrado: Concepções e contradições. São Paulo: Cortez, 2005, p. 83 a 105.

GARCIA, N. M. D.; ROCHA, J. V.; COSTA, R. Z. V. Área de Ciências da Natureza, Matemática e suas Tecnologias: algumas contribuições para sua organização: FíSICA. In: KUENZER, A. (Org.). Ensino Médio: Construindo 
uma proposta para os que vivem do trabalho. 6. ed. São Paulo: Cortez, 2009. p. 138 a 151.

JACQUES, V.; VERGINIO, M. R. C.; MINSK, M. P. O Ensino de Física e o Curso Técnico em Edificações. In: SEMINÁRIO DE PESQUISA, EXTENSÃO E INOVAÇÃO DO IF-SC, 1‥ Campus Criciúma. 2011. Disponível em: http://periodicos.ifsc.edu.br/index.php/rtc/article/viewFile/362/287. Acesso em: 30 nov. 2018.

KAWAMURA, M. R. D.; HOSOUME, Y. A contribuição da Física para um novo Ensino Médio. Física na Escola, v. 4, n. 2, p. 22-27, 2003. Disponível em: http://portal.mec.gov.br/seb/arquivos/pdf/EnsMed/expensfisica.pdf. Acesso em: 14 jul. 2019.

LUDKE, M. Pesquisa em educação: abordagens qualitativas. 2. ed. Rio de Janeiro: EPU, 2013.

MENEZES, L. C. de. Uma física para o novo ensino médio. Física na escola, v. 1, n. 1, p. 7, 2000. Disponível em:

http://www1.fisica.org.br/fne/phocadownload/Vol01-Num1/artigo21.pdf. Acesso em: 14 jul. 2019.

MORAES, R. Análise de Conteúdo. Revista Educação, Porto Alegre, v. 22, n. 37, p. 7-32, 1999. Disponível em: bit.ly/2P1LGq8. Acesso em: 14 jul. 2019.

MOREIRA, M. A. Ensino de física no Brasil: retrospectiva e perspectivas. Revista Brasileira de Ensino de Física, São Paulo, v. 22, n. 1, p. 94-99, 2000. Disponível em: http://www.sbfisica.org.br/rbef/pdf/v22_94.pdf. Acesso em: 14 jul. 2019.

PROJETO PEDAGÓGICO DE CURSO. PPC Curso Técnico Em Edificações Nível Médio Integrado. Instituto Federal do Pará. Santarém. 2016. (material em PDF).

RAMOS, F. R. O.; HEINSFELD, B. D. S. S. Reforma do ensino médio de 2017 (Lei no 13.415/2017): um estímulo à visão utilitarista do conhecimento. In: CONGRESSO NACIONAL DE EDUCAÇÃO. 2017. p. 18284-18300. Disponível em: https://educere.bruc.com.br/arquivo/pdf2017/24107_11975.pdf. Acesso em: 14 jul. 2019.

RAMOS, M. 'É o esvaziamento do currículo, seja pela dualidade, seja pela fragmentação'. [Entrevista concedida a] André Antunes. Escola Politécnica de Saúde Joaquim Venâncio - FIOCRUZ. 2018. Disponível em: bit.ly/2rb0cE7. Acesso em: 14 jul. 2019.

RAMOS, M. Possibilidades e desafios na organização do currículo integrado. In: FRIGOTTO, G.; CIAVATTA, M.; RAMOS, M. (Org.). Ensino Médio Integrado: Concepções e contradições. São Paulo: Cortez, 2005, p. 106 a 127. 